\title{
Challenges of managing diabetes in Iran: meta-synthesis of qualitative studies
}

\author{
Mohammad Mohseni ${ }^{1}$, Tahereh Shams Ghoreishi' ${ }^{2}$ Sousan Houshmandi ${ }^{3}$, Ahmad Moosavi ${ }^{4}$, \\ Saber Azami-Aghdash ${ }^{5}$ and Zoleykha Asgarlou ${ }^{6^{*}}$
}

\begin{abstract}
Background: Although several diabetes management and control programmes are introduced in Iran, many patients do not achieve diabetes-related clinical goals as recommended. The aim of this study was to identify the qualitative evidence for the challenges regarding diabetes management.

Methods: A systematic review of qualitative studies following PRISMA guidelines was undertaken. Scopus, PubMed, Science Direct, and Web of Knowledge were searched as well as Persian databases including Magiran, Irandoc and SID from inception to August 2019. The included Studies were either in English- or Persian-language qualitative studies reporting the perspectives of patients, their relatives, or healthcare service providers. Content of the findings were analysed and organized according to Chronic Care Model framework.

Results: Twelve studies met the inclusion criteria. Six main themes were identified including holistic understanding of patients, leadership and governance difficulties, service delivery, workforce, financing, and information and research.

Conclusion: Challenges regarding the management of diabetes in Iran is multifaceted. Reforming the health care system or developing complementary strategies is essential to improve suitable health care model for patients with chronic conditions such as diabetic patients.
\end{abstract}

Keywords: Systematic review, Qualitative studies, Diabetes, Iran

\section{Background}

Diabetes continue to constitute a crucial health issue on a global scale. It is estimated that, only in 2013, approximately 380 million adults were living with diabetes (all types), and this number will rise to 590 million by 2035 [1]. The reports also indicate that regarding the prevalence of diabetes worldwide, the Middle East and North Africa region are ranked 1st [1].

In Iran, as the second-largest country in the Middle East, diabetes is a major public health problem because of its high prevalence rate, increasing incident rate, and

\footnotetext{
* Correspondence: zol.asg59@gmail.com

${ }^{6}$ Khoy University of Medical Sciences, Khoy, Iran

Full list of author information is available at the end of the article
}

economic burden [2]. Mortality associated with diabetes in Iran continue to increase; age standardized mortality rate by diabetes is increased from 8.7 in 2000 to 11.3 in 2015 [3]. Diabetes has also important economic implications in the country. It's estimated that average percapita medical cost for Iranian patients with diabetes was equal to $\$ 843$ only in 2009 [4]. In addition to its high direct health care expenditure, diabetes also is a strong risk factor for other chronic conditions, such as cardiovascular disease [5]. For example, of $\$ 843$ per capita cost of diabetes, $\$ 412(49 \%)$ was related to diabetes complications [4].

It is now well-documented that a good healthcare services and healthy life style can prevent diabetes related complications and enhance the quality of the patient's

(c) The Author(s). 2020 Open Access This article is licensed under a Creative Commons Attribution 4.0 International License, which permits use, sharing, adaptation, distribution and reproduction in any medium or format, as long as you give appropriate credit to the original author(s) and the source, provide a link to the Creative Commons licence, and indicate if changes were made. The images or other third party material in this article are included in the article's Creative Commons licence, unless indicated otherwise in a credit line to the material. If material is not included in the article's Creative Commons licence and your intended use is not permitted by statutory regulation or exceeds the permitted use, you will need to obtain permission directly from the copyright holder. To view a copy of this licence, visit http://creativecommons.org/licenses/by/4.0/ The Creative Commons Public Domain Dedication waiver (http://creativecommons.org/publicdomain/zero/1.0/) applies to the data made available in this article, unless otherwise stated in a credit line to the data. 
life [6]. On the other hand, optimal diabetes management can result in considerable reduction in healthcare expenditure [7]. Although several diabetes management and control programmes are introduced in Iran, the current increasing diabetes related mortality and complication costs reflect suboptimal management of diabetes in the country. According to several reports, Iranian diabetic patients mostly do not get required qualitative services [8] and their usually have poor metabolic (glycemic) control [9, 10]. For example, a nationwide prospective analysis of data for 30,202 patients found that only $13.2 \%$ of patients with diabetes achieved satisfactory glycemic control target [11]. This finding reveals challenges regarding current diabetes management in Iran.

Identifying the challenges in diabetes management is important so that policymakers can plan and intervention with it based on the current evidences. In this regards, qualitative approaches can address this subject deeply [12]. Regarding the management of diabetes in Iran, several studies have been conducted to identify major challenges. To the best of our knowledge, there are no qualitative systematic review that address challenges of diabetes management in Iran from perspectives of main stakeholders. Thus, the objective of this study is to acquire a more comprehensive understanding of patients', their relatives', or their healthcare providers' perspective on the challenges that Iranian health system faces regarding managing diabetes. The results of this systematic review will help healthcare policy makers and providers to develop policy and interventions in improving diabetes management that are aligned with key stakeholders' perspectives.

\section{Methods}

A systematic literature review and evidence synthesis of qualitative evidence on challenges of diabetes management in Iran was conducted based on the Preferred Reporting Items for Systematic Reviews and Meta-Analyses (PRISMA) [13]. Systematic search of Scopus, PubMed, Science Direct, and Web of Knowledge was made, in addition to three Iranian databases (MagIran, Irandoc and Scientific Information Database (SID) databases), from inception to August 2019. The reference lists of the relevant studies were also hand-searched to capture additional potentially relevant citations. The retrieved records were handled using Endnote V.X5. The search strategy combined subject heading/keyword searches for "diabetes", keyword search for "Iran" and search filters for retrieving qualitative studies recommended by McMaster University Health Information Research Unit [14]. An example search strategy is presented in Appendix.
Peer-reviewed studies that were published in English/ Persian and provided original qualitative data regarding the perspectives of patients with diabetes (all types), their relatives, or healthcare providers/policy makers on diabetes management challenges were included. Studies that either concerned with a specific dimension of diabetes management (such as self-care or a diabetes related specific intervention/policy), or more general aspects of diabetes management were included. On the other hand, quantitative studies and papers with closedended questionnaires were excluded. One of the authors (MM) conducted the search and eliminated duplicated records. Next, two of the authors ( $\mathrm{SH}$ and $\mathrm{ZA}$ ) independently screened the titles of retrieved citations and eliminated irrelevant studies. The reviewers independently evaluated the abstracts of the remaining studies and possible relevant studies remained for further assessment. In the next step, each reviewer read the fulltext of the remaining studies for inclusion of citations considered as definitely meeting the eligibility criteria. Disagreements were resolved via a discussion between reviewers.

All included articles were critically appraised by Critical Appraisal Skills Programme (CASP) tool [15]. In this review, two of the researchers (AM, TSG) assessed each study's quality independently, and after conferral of findings and scores, a decision was made about inclusion.

A pre-piloted data extraction table was used to extract the included studies' data. The table includes: name of first author, publication year, study setting, study aim, participants, and key findings regarding pertinent themes relating to diabetes management challenges. To analyse and synthesize extracted data, thematic framework analysis based on the Modified WHO key components of health systems was used [16]. The framework structures key concepts in integrated care for patients with multiple chronic conditions can be used by different stakeholders to guide development, implementation, description, and evaluation of health system response regarding chronic conditions. This framework includes: holistic understanding of the patients, service delivery, leadership \& governance, workforce, financing, technologies \& medical products, and information \& research.

Extraction was carried out by (MM). Another reviewer (SAA) looked on the extraction process in more detail to ensure suitability of data extraction. Differences in judgments were resolved by a discussion between reviewers.

\section{Results}

The search result yielded a total of 708 studies. After removing 46 duplicates, the title and abstract of the remaining 662 studies were screened for relevancy. Six hundred seventeen obviously irrelevant studies were 
excluded. Forty five citations were selected for full-text review, of which 12 studies were included. Figure 1 describes the details of literature identification and selection process.

\section{Overview of the included studies}

Included studies were published between 2009 and 2019 . Five articles [17-21] focused on patients, two [22, 23] on healthcare providers/experts, and five on mixture of these groups. The total population sample included 188 patients, 2 relatives, and 25 healthcare providers/experts. Nine studies [17-19, 22, 24-27] used face to face qualitative interviews, one [21] used focus group discussions, one used mixture of interviews and focus group discussions [28], and one used mixture of interviews and document review [23].

\section{Quality of studies}

The overall quality assessment of included studies was performed by rating CASP items (Table 1). All of the included studies had a clear statements of the research objectives and appropriate qualitative methodology and descriptions of data analysis techniques were generally provided.

\section{Emerged themes}

Our findings regarding the challenges of diabetes management in Iran reported below, using the seven dimensions of modified WHO components of health systems (Holistic understanding of the patients, service delivery, leadership and governance, workforce, financing, technologies and medical products) as a guide (Table 2).

\section{Holistic understanding of the patients}

Overall, participants perceived the lack of a holistic understanding of diabetic patients' health, abilities, needs and environment. In this regards, four sub-categories emerged: (1) insufficient attention to patients, (2) lack of patients trust in healthcare and healthcare providers, (3) insufficient family support and, (4) insufficient community support.

\section{Insufficient attention to patients}

Patients highlighted their expectations on the healthcare providers, in relation to feeling listening to and getting attention. They perceived that they receive insufficient attention from the therapy team [24]. Most of participants complained about the insufficient time physician are spending with clients [21].

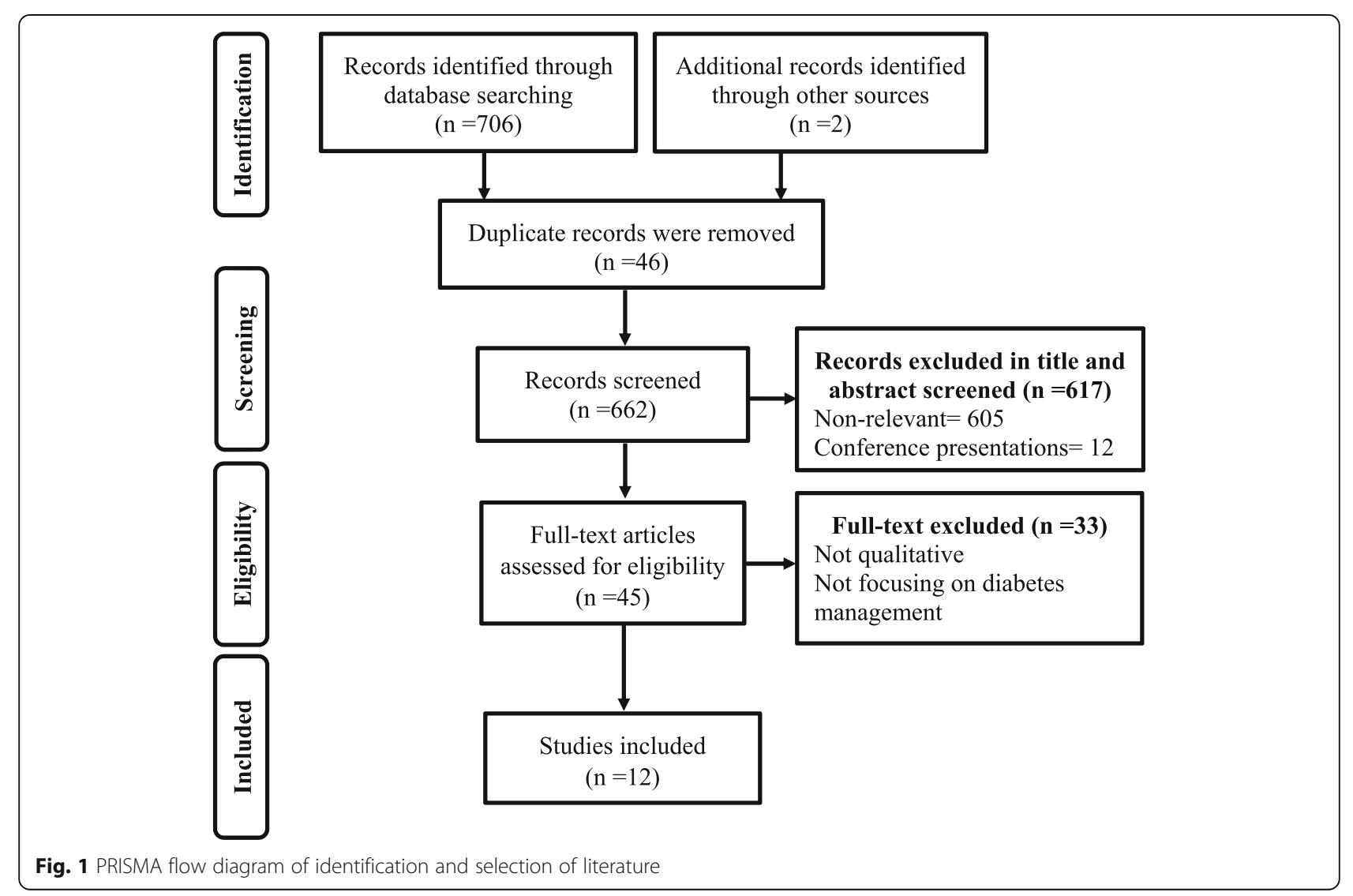




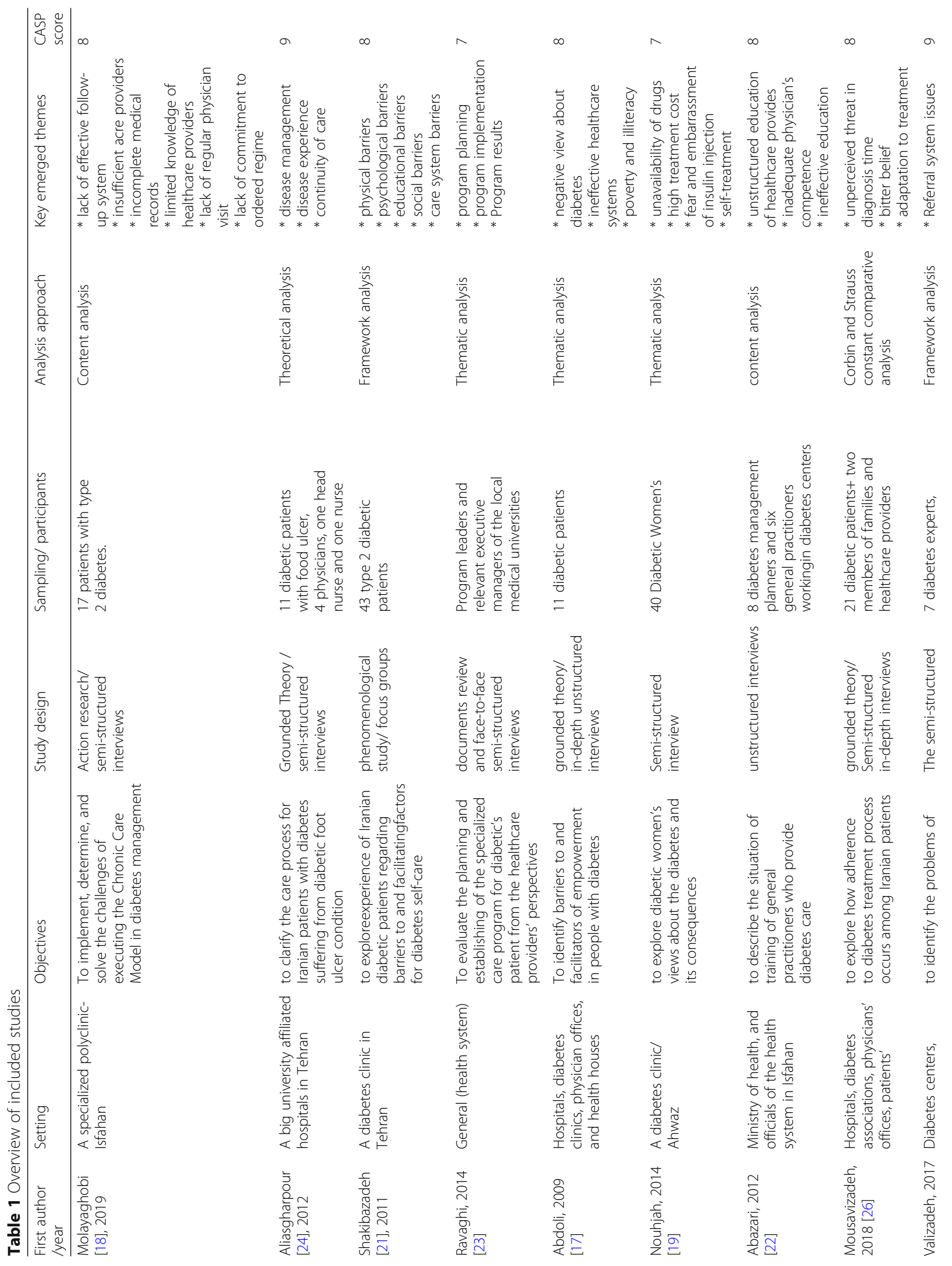


Mohseni et al. BMC Health Services Research

(2020) 20:534

Page 5 of 12

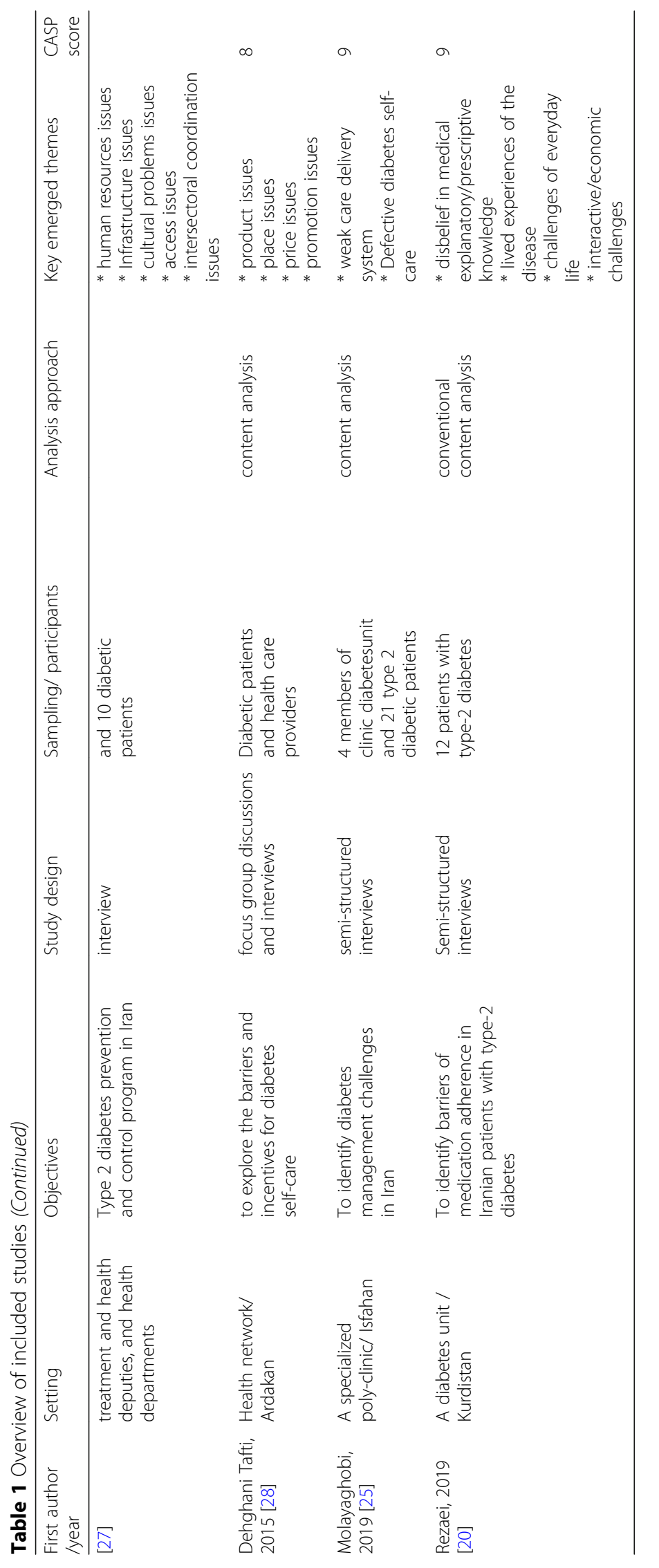




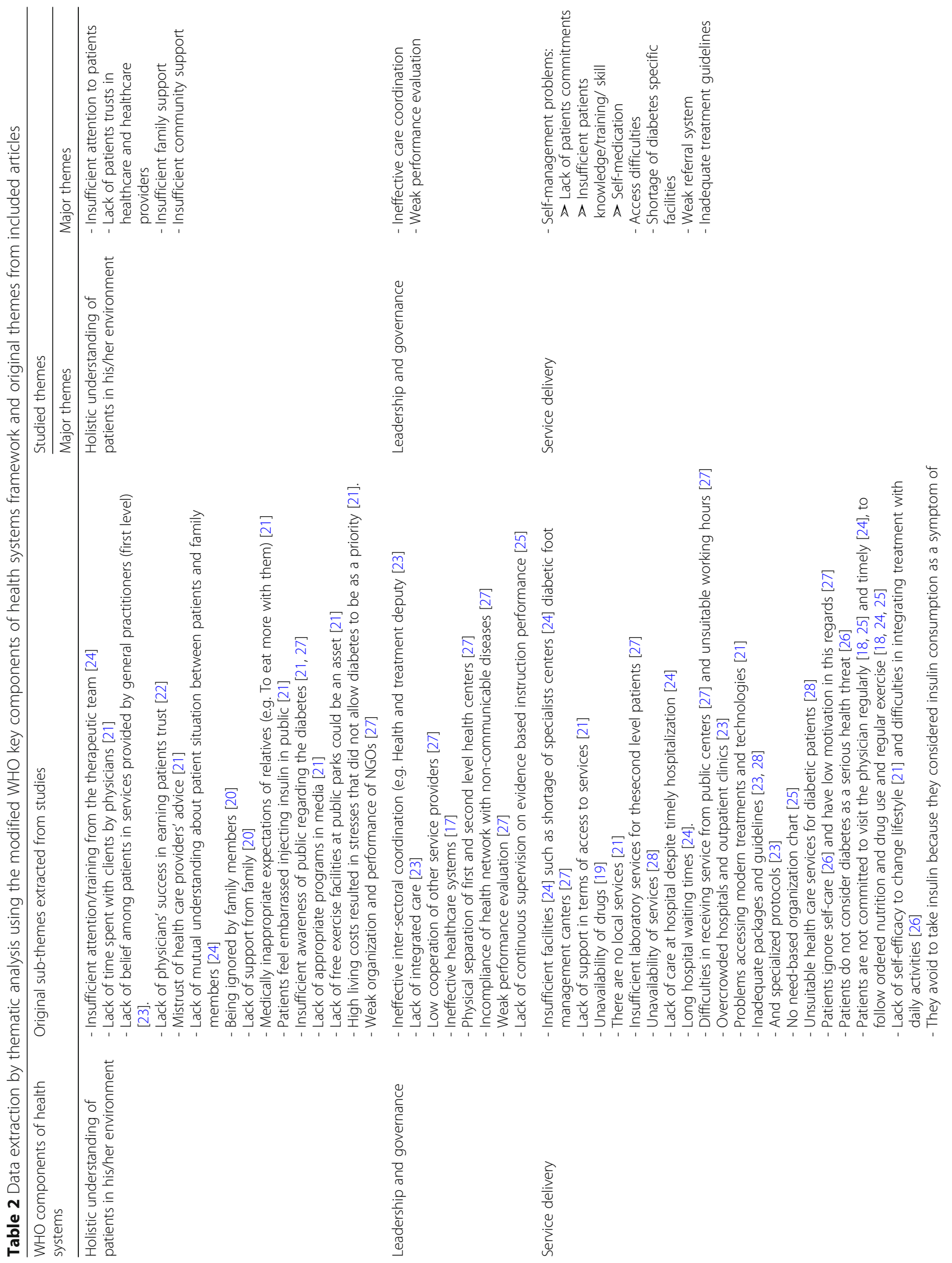




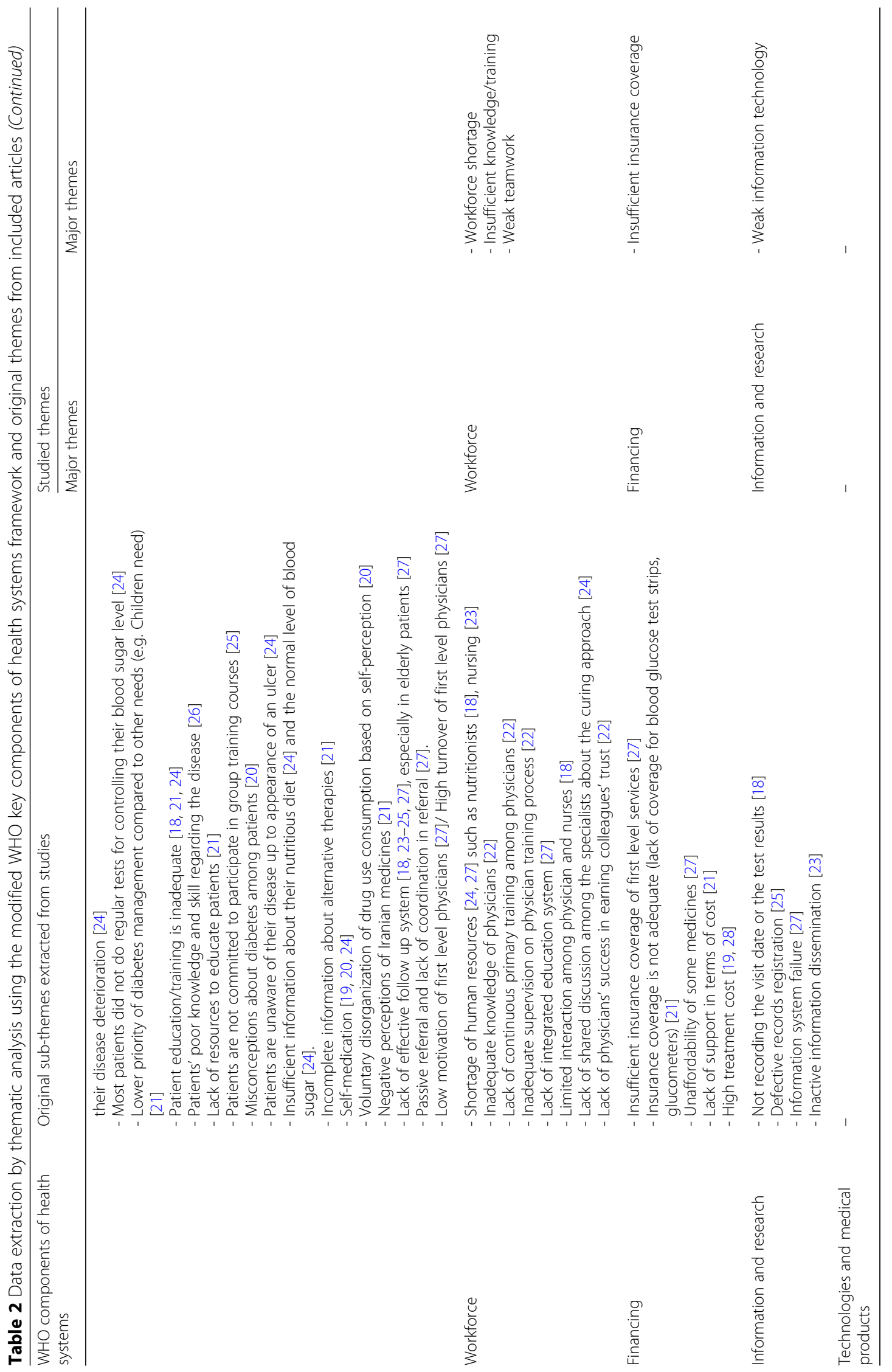




\section{Lack of patients' trusts in healthcare and healthcare providers}

Our results demonstrated the need patients of patients trust in their healthcare professionals. Multiple trust related issues were raised including lack of belief among patients in services provided by general practitioners (first level) [23], lack of physicians' success in earning patients confidence [22], and mistrust of health care providers' advice [21].

\section{Insufficient family support}

The lack of family support was found to be a challenge for patients with diabetes. Several patients reported misunderstanding with family members about their situation [24]. Some of them reported that they are being ignored by family members [20]. Moreover, family members were also seen as a barrier to the diabetes related healthy lifestyles.

\section{Insufficient community support}

Community support was an area in which frustration was often expressed. The participants believed that there is insufficient awareness of public regarding the diabetes $[21,27]$. They criticized the current negative perception of community members' regarding patients with diabetes, thus they felt embarrassed injecting insulin in public [21]. Moreover, lack of appropriate programs in media was seen as an important sign of poor community support [21]. One of the studies found that lack of free exercise facilities at public parks is a concern for patients with diabetes [21]. High living cost was another subdomain in this area, preventing diabetes to be a priority [21]. Finally, one of the included studies found poor performance of non-governmental organization (NGOs) another challenge regarding community support [27].

\section{Leadership and governance difficulties}

We found that successful management of diabetes in Iran is hindered by overall health system's leadershipand governance-related issues. There were two subthemes related to leadership and governance: Ineffective care coordination and weak performance evaluation.

\section{Ineffective care coordination}

Participants expected that, as a chronic condition, patients with diabetes should receive the healthcare services through a well-coordinated health system. They were of opinion that provided healthcare service lack integration [23]. They also perceived low cooperation of other service providers [27] and ineffective inter-sectoral coordination (e.g. health and treatment deputy) [23], indicating incompliance of health network with noncommunicable diseases [27].

\section{Weak performance evaluation}

According to the participants' perspectives, performance assessment in diabetes care is inappropriate. The main challenges are lack of effective [27] and continuous supervision on evidence based instructional performance [25].

\section{Service delivery}

Participants consistently described service delivery constraints as important challenges, especially in relation to self-management practice or general aspects of care. There were five subthemes related to service delivery: (1) self-care management problems, (2) access difficulties, (3) shortage of diabetes specific facilities, (4) weak referral system and, (5) inadequate treatment guidelines.

\section{Self-care management problems}

According to participants' point of view, challenges regarding self-care management hinder achievement of good diabetes control. It was determined that "self-management problems" contains three sub-categories: (1) Lack of patients commitment, (2) insufficient patients knowledge/training/ skill, and (3) Self-medication.

The first subcategory of "lack of patient's commitment" regarding self-management was strongly explained as an important challenge. We found that patients ignore self-care [26] and have low motivation in this regards [27]. Sometime, they do not consider diabetes as a serious health threat [26] or priority [21] and are not committed to visit the physician regularly [18, 25] and timely [24]. Moreover, most of them did not do regular tests for controlling their blood sugar level [24]. In addition, they do not comply with diabetic food/ healthy diet, regular medication regimen and other essential life-style behaviors such as regular exercise [18, $24,25]$. They are also not committed to participate in training/awareness courses related to diabetes [25].

Other self-management barriers includes insufficient patients' knowledge/training/skill. Patients have no selfefficacy to change their lifestyle (as a critical selfmanagement dimension) [21] and have difficulties in integrating treatment with their daily activities [26]. Most of participants explained that they do not receive appropriate training on self-control $[18,21,24]$ that may lead to patients' poor knowledge and skill regarding the disease and its management $[20,26]$. This include insufficient information about appropriate healthy diet [24] normal level of blood sugar [24] and alternative therapies [21]. The issue of poor knowledge of patients was emphasized strongly in some cases; sometimes patients are unaware of their disease processes till their start developing complications [24].

The third area in challenges regarding self- management is concerned with the self-medication [19, 20, 24]. 
Patients with diabetes, sometimes, do not seek any formal treatments. In this circumstance, they utilize drugs based on their self-perception without any medical command [20]. One of the included studied found that patients' negative perceptions of Iranian medicines may deteriorate self-medication practice issues [21].

\section{Access difficulties}

According to participants' perspectives, access to diabetes care appears inadequate $[19,21,24,27,28]$. Sometime, diabetes patients have difficulties in obtaining access to a wide range of services including medications [19], modern treatment and technologies [21], laboratory services [27], service from public centers [27], and local services [21]. They also mentioned that their access to care is restricted by long waiting times in hospitals [24], by unsuitable working hours of outpatient settings [27], or by overcrowded hospitals and outpatient clinics [23]. Patients also explained their experience of lack of access to inpatient care despite timely hospitalization [24].

\section{Shortage of diabetes specific facilities}

Several participants report inadequate diabetic specific specialist facilities like diabetic foot center as a challenge to those with diabetes [24, 27].

\section{Weak referral system}

One of the most common mentioned challenge of diabetes management in Iran was weak referral system. In this regards, according to participants, the common problems lack of effective referral and follow up system $[18,23-25,27]$, especially in elderly patients [27].

\section{Inadequate treatment guidelines}

In the care provision of diabetes, there is need for using evidence-based guidelines as highlighted by the participants. Some studies found that patients with diabetes do not receive diabetic care in line with evidence based practice and guidelines $[23,28]$. They believed that the provided health cares are not organized based on patients' need [25] and preferences [28].

\section{Workforce}

Included studies highlighted multiple workforce related issues hindering diabetes management in Iran with three subthemes: (1) workforce shortage, (2) insufficient knowledge/training and, (3) weak teamwork.

\section{Workforce shortage}

Several respondents expressed concerns over shortage of human resources [24, 27] such as nutritionists [18] and nurses [23].

\section{Insufficient knowledge/training}

Inadequate knowledge and training of healthcare providers inform of continuous medical education/training was reported as an important barrier to better management of patients with diabetes. Participants perceived lack of continuous [22] and integrated [27] training among physicians, inadequate supervision on physician training process [22], and therefore their inadequate knowledge [22].

\section{Week teamwork}

Team work issues were reported by several participants as important challenges of managing diabetes in Iran. According to participants' point of view in including studies, there is not an optimal cross-disciplinary relationship among healthcare providers. They believed that there are limited interactions among physician and other healthcare providers including nurses [18]. In terms of physician-physician relationship, participants mentioned that patients experience a treatment condition that lacks optimal shared discussion among the specialists about the curing approach [24]. Participants cited that physicians fail in earning colleagues' trust [22].

\section{Financing}

We found that financial support is a key issue that participants care about. In this regards, only one subtheme emerged and is discussed below:

\section{Inadequate insurance coverage}

Insufficient health insurance, including the insufficient insurance coverage of first level services [27] and lack of coverage for diabetes related equipment and test (e.g. blood glucose test strips, glucometers) [21], associated financial strain of some expensive medications and treatments $[19,21,28]$, was reported by participants.

\section{Information and research}

Regarding the information and research dimension, only one subtheme emerged and is discussed below:

\section{Weak information technology}

Findings of this research indicate that systematic recording of individual level health and healthcare data and utilizing them in care process is one of the important concerns of diabetes care stakeholders. In this area, participants perceived information system failure [27] and poor records registrations [25] that act as an obsolete information technology [23]. They believed that important piece of data such as visit date or the test results are not been recorded [18]. 


\section{Discussion}

This meta-synthesis sought to provide a comprehensive understanding of diabetes management challenges from the perspectives of the main stakeholders of diabetes care in Iran. The review identified six major themes regarding to diabetes management in the country including: holistic understanding of patients, leadership and governance, service delivery, workforce, financing, and information and research. The results of this study covered broad dimensions of the modified WHO key components of health systems. However, none of the included studies actually addressed the "Technologies and medical products" theme of the modified WHO key components of health system.

In the present review, a wide variety of challenges regarding diabetes management were identified, in which many of them were similar to challenges identified in other studies around the world [29-31]. However, some cultural/context specific barriers in diabetes management were identified such as counter to self-care expectations of relatives (e.g. to eat more with them) [21], lower priority of diabetes management compared to other needs (e.g. children need) [21], and Selfmedication [19, 20, 24].

Findings from the included studies determined that many of diabetic patients and their preferences and needs are not being understood appropriately. We found that teamwork is strikingly absent in care provision process of diabetes management. Our review suggests that knowledge barriers were commonly reported by participants. Participants complained about lack of diabetes management skills/knowledge among patients, their relatives, and even healthcare providers. This results, however, is in contrast with Moser et al. [32] that found older adults with type 2 diabetes had a good control over their blood glucose and they followed the recommended nutritional diet; they receive effective training support from diabetes specialists and find answers to their caring questions.

Medication related issues comprised a wide list of emerged sub-themes, of which Insulin utilization was frequently highlighted in included studies. We found that insulin is underutilized among Iranian diabetic patients. This finding supports Sarayani et al. results [33]. In a time-series study of pharmaceuticals wholesale data for Iran, they found that insulin utilization only comprised $17 \%$ of total antidiabetic consumption in 2012 [33]. This is very low compared to European countries; share of insulin utilization in European countries was 30\% in 2003 [34]. Possible explanations of this underutilization in Iran could be inadequacy of physicians' knowledge about clinical guidelines as well as patients' concerns about insulin injection [21, 35].
The national model of non-communicable diseases prevention and control has yet to be implemented [36], and therefore the findings of this review afford opportunity to anticipate the main difficulties and plan solutions taking into account of the identified challenges. First, the results of our review suggest that educational interventions (for patients and their relatives and healthcare providers) may facilitate diabetes care management. Second, partnership that is built up between healthcare providers and between patients and their care givers may facilitate diabetes management. In practice, health care system should aim for continuity of care so the opportunity occurs regarding better information sharing between patients and their physicians [37], enhanced understanding of the patient's needs [38], and earlier detection and management of serious disease outcomes [37]. In addition, we found that sometimes medication access is limited by insurance companies. Pharmacy benefit management strategies of health insurers need to be changed to facilitate access to diabetes-related medications/equipment.

\section{Strengths and limitations of the study}

This review gathered evidence of diabetes management difficulties in Iran from the perspective of a wide involved groups, namely patients, their relative, and healthcare providers/policymakers, which can help systematic management of diabetes care. In addition, in this review, we focused on qualitative studies to provide an in-depth exploration of the issue. However, this study have some limitations that should be considered when interpreting the results. First, decisions about the search strategy and database selection may influence the retrieving of all of the relevant articles [39]. Another limitation is the fact that this review addresses only those challenges reported by participants that may not be acknowledged of all potential barriers regarding diabetes management in Iran.

\section{Conclusion}

The results of this systematic review are evidence for existence of fundamental weaknesses in diabetes management in Iranian healthcare system. The modified WHO key components of health systems are reflected in the emerged challenges of this study. Iranian healthcare system need a new comprehensive integrated care model for management of chronic health conditions like diabetes, in which the system improves from fragmented, disease-centered, inaccessible care to a patient-centered, holistic and continuous care with healthcare provides alliance. The results of this systematic review can contribute to a better implementation of diabetes management programmes in Iran and similar to many developing countries. 


\section{Appendix Search strategy}

1: diabetes/.exp. or (diabet", blood glucose or hyperglycemia or glucose or hemoglobin A1c or insulin):ti,ab.

2: interview/.exp. or qualitative research/.exp. or (qualitative study or qualitative research or focusgroup* or experience* or attitude): ti, ab.

3: Iran or Iranian or Persia.

4: \#1 AND \#2 AND \#3.

\section{Abbreviations}

PRISMA: Preferred Reporting Items for Systematic Reviews and MetaAnalyses; SID: Scientific Information Database; CASP: Critical Appraisal Skills Programme; WHO: World Health Organization; NGO: Non-governmental Organization

\section{Acknowledgements}

Not applicable.

\section{Authors' contributions}

MM, SAA and AM and contributed to the concept and design of the study. MM, TSG, SH and ZA contributed to the analysis and interpretation of the data. AM and SAA contributed to the critical revision of the article and writing of the manuscript. All authors have read and approved the final manuscript.

\section{Funding}

The authors received no financial support for the authorship and/or publication of this review.

\section{Availability of data and materials}

All data generated or analysed during this study are included in this published article [and its supplementary information files].

\section{Ethics approval and consent to participate}

Not applicable.

\section{Consent for publication}

Not applicable.

\section{Competing interests}

The authors declare that they have no competing interests.

\section{Author details}

'Health Management and Economics Research Center, Iran University of Medical Sciences, Tehran, Iran. ${ }^{2}$ Department of Midwifery, School of Nursing and Midwifery, Zanjan University of Medical Sciences, Zanjan, Iran. ${ }^{3}$ Department of Midwifery, School of Nursing and Midwifery, Ardabil University of Medical Sciences, Ardabil, Iran. ${ }^{4}$ Department of Health and Community Medicine, Dezful University of Medical Sciences, Dezful, Iran. ${ }^{5}$ Tabriz Health Services Management Research Center, Health Management and Safety Promotion Research Institute, Tabriz University of Medical Sciences, Tabriz, Iran. ${ }^{6}$ Khoy University of Medical Sciences, Khoy, Iran.

Received: 4 January 2020 Accepted: 19 March 2020

Published online: 12 June 2020

\section{References}

1. Guariguata L, Whiting DR, Hambleton I, Beagley J, Linnenkamp U, Shaw JE. Global estimates of diabetes prevalence for 2013 and projections for 2035. Diabetes Res Clin Pract. 2014;103(2):137-49.

2. Esteghamati A, Khalilzadeh O, Anvari M, Meysamie A, Abbasi M, Forouzanfar M, Alaeddini F. The economic costs of diabetes: a population-based study in Tehran, Iran. Diabetologia. 2009;52(8):1520-7.
3. Veisani Y, Khazaei S, Jenabi E, Delpisheh A. Diabetes mortality and morbidity trends and related risk factors in Iranian adults: an appraisal via current data. J Tehran Univ Heart Center. 2018;13(4):195-7.

4. Javanbakht M, Baradaran HR, Mashayekhi A, Haghdoost AA, Khamseh ME, Kharazmi E, Sadeghi A. Cost-of-illness analysis of type 2 diabetes mellitus in Iran. PLoS One. 2011:6(10):e26864.

5. Bonakdaran S, Ebrahimzadeh S, Noghabi S. Cardiovascular disease and risk factors in patients with type 2 diabetes mellitus in Mashhad, Islamic Republic of Iran; 2011.

6. Association AD. Standards of medical care in diabetes-2015 abridged for primary care providers. Clin Diab. 2015;33(2):97.

7. Wan Q, Harris M, Jayasinghe U, Flack J, Georgiou A, Penn D, Burns J. Quality of diabetes care and coronary heart disease absolute risk in patients with type 2 diabetes mellitus in Australian general practice. BMJ Qual Saf. 2006;15(2):131-5.

8. Shaghaghi A, Ahmadi A, Matlabi H. Iranian patients require more pertinent care to prevent type 2 diabetes complications. Adv Prev Med. 2014;2014: 409391.

9. Heshmati H, Behnampour N, Khorasani F, Moghadam Z. Prevalence of chronic complications of diabete and its related factors in referred type 2 diabetes patients in Freydonkenar diabetes center. J Neyshabur Univ Med Sci. 2014;1(1):36-43.

10. Delpisheh A, Azizi H, Dantalab Esmaeili E, Haghiri L, Karimi G, Abbasi F. The quality of care and blood sugar control in type II diabetic patients of rural areas under the care by family physicians. Iran J Diab Lipid Disord. 2016; 14(3):189-98.

11. Esteghamati A, Larijani B, Aghajani MH, Ghaemi F, Kermanchi J, Shahrami A, Saadat M, Esfahani EN, Ganji M, Noshad S, et al. Diabetes in Iran: prospective analysis from first Nationwide diabetes report of National Program for prevention and control of diabetes (NPPCD-2016). Sci Rep. 2017;7(1):13461.

12. Refaie Shirpak K, Guruge S, Chinichian M. Meta-synthesis of qualitative research in health sciences. Iran J Epidemiol. 2010;6(1):51-7.

13. Moher D, Liberati A, Tetzlaff J, Altman DG. Preferred reporting items for systematic reviews and meta-analyses: the PRISMA statement. Ann Intern Med. 2009;151(4):264-9.

14. Search filters for MEDLINE in ovid syntax and the PubMed translation [https://hiru.mcmaster.ca/hiru/HIRU_Hedges_MEDLINE_Strategies. aspx\#Qualitativ].

15. CASP qualitative checklist [https://casp-uk.net/wp-content/uploads/2018/01/ CASP-Qualitative-Checklist-2018.pdf].

16. Leijten FR, Struckmann V, van Ginneken E, Czypionka T, Kraus M, Reiss M, Tsiachristas A, Boland M, de Bont A, Bal R. The SELFIE framework for integrated care for multi-morbidity: development and description. Health Policy. 2018;122(1):12-22.

17. Abdoli S, Ashktorab T, Ahmadi F, Parvizi S. Barriers to and facilitators of empowerment in people with diabetes. Iran J Endocrinol Metabol. 2009; 10(5):455-64.

18. Molayaghobi NS, Abazari P, Taleghani F, Iraj B, Etesampour A, Zarei A, Hashemi H, Abasi F. Overcoming challenges of implementing chronic care model in diabetes management: an action research approach. Int J Prev Med. 2019;10:13

19. Nouhjah S, Fayazi F. A qualitative study to define diabetic women's views about health, illness, complications and experienced restrictions, attending Ahvaz diabetes clinic. Iran J Endocrinol Metabol. 2014;16(4):235-44.

20. Rezaei M, Valiee S, Tahan M, Ebtekar F, Gheshlagh RG. Barriers of medication adherence in patients with type-2 diabetes: a pilot qualitative study. Diabetes Metab Syndr Obes Targets Ther. 2019;12:589.

21. Shakibazadeh E, Larijani B, Shojaeezadeh D, Rashidian A, Forouzanfar M, Bartholomew L. Patients' perspectives on factors that influence diabetes self-care. Iran J Public Health. 2011;40(4):146.

22. Abazari $P$, Vanaki Z, Mohammadi E, Amini M. Challenges of training diabetes nurse educator in Iran. Iran J Nurs Midwifery Res. 2012;17(3):187.

23. Ravaghi H, Sajadi HS, Ghotbi M, Sarvarizadeh S, Sharbafchizadeh N, Kermanchi J. Evaluation of an urban phase of the specialized care program for diabetes in Iran: providers' perspectives. Int J Prev Med. 2014:5(8):1013.

24. Aliasgharpour $M$, Nayeri ND. The care process of diabetic foot ulcer patients: a qualitative study in Iran. J Diab Metab Disord. 2012;11(1):27.

25. Molayaghobi NS, Abazari P, Taleghani F, Iraj B. Diabetes management challenges in Iran: a qualitative content analysis. J Nurs Manag. 2019:27:1091-7.

26. Mousavizadeh SN, Ashktorab T, Ahmadi F, Zandi M. From negligence to perception of complexities in adherence to treatment process in people with diabetes: a grounded theory study. Iran J Med Sci. 2018;43(2):150. 
27. Valizadeh R, Vali L, Bahaadinbeigy K, Amiresmaili M. The challenges of Iran's type 2 diabetes prevention and control program. Int J Prev Med. 2017:8:175.

28. Dehghani Tafti AA, Mazloomymahmoodabad SS, Morowatisharifabad MA, Khalilzadeh SH, Rezaeipandari $\mathrm{H}$. Barriers and incentives of self-care from the view of diabetic patients and their service providers using the social marketing model in Ardakan, Iran. J Qual Res Health Sci. 2015;3(4):317-30.

29. Mc Hugh S, O'Mullane M, Perry IJ, Bradley C. Barriers to, and facilitators in, introducing integrated diabetes care in Ireland: a qualitative study of views in general practice. BMJ Open. 2013;3(8):e003217.

30. Sibounheuang P, Sookanakenun P, Kittiboonyakun P. Patients' and healthcare providers' perspectives on diabetes management: a systematic review of qualitative studies. Res Soc Adm Pharm. 2019. https://doi.org/10 1016/j.sapharm.2019.09.001

31. Alberti H, Boudriga N, Nabli M. Primary care management of diabetes in a low/middle income country: a multi-method, qualitative study of barriers and facilitators to care. BMC Fam Pract. 2007;8(1):63.

32. Moser A, van der Bruggen $H$, Widdershoven $G$, Spreeuwenberg C. Selfmanagement of type 2 diabetes mellitus: a qualitative investigation from the perspective of participants in a nurse-led, shared-care programme in the Netherlands. BMC Public Health. 2008;8:91.

33. Sarayani A, Rashidian A, Gholami K. Low utilisation of diabetes medicines in Iran, despite their affordability (2000-2012): a time-series and benchmarking study. BMJ Open. 2014:4(10):e005859.

34. Melander A, Folino-Gallo P, Walley T, Schwabe U, Groop P-H, Klaukka T, Vallano A, Laporte J-R, Gallego M, Schiappa M. Utilisation of antihyperglycaemic drugs in ten European countries: different developments and different levels. Diabetologia. 2006;49(9):2024-9.

35. Peimani M, Tabatabaei-Malazy O, Heshmat H, Sanjari M, Pajouhi M. Knowledge, attitude and practice of physicians in the field of diabetes and its complications; A pilot study. J Diab Metab Disord. 2010;9:10.

36. Peykari N, Hashemi H, Dinarvand R, Haji-Aghajani M, Malekzadeh R, Sadrolsadat A, Sayyari AA, Asadi-Lari M, Delavari A, Farzadfar F. National action plan for non-communicable diseases prevention and control in Iran; a response to emerging epidemic. J Diab Metab Disord. 2017;16(1):3.

37. Saultz JW, Lochner J. Interpersonal continuity of care and care outcomes: a critical review. Ann Fam Med. 2005;3(2):159-66.

38. Hänninen J, Takala J, Keinänen-Kiukaanniemi S. Good continuity of care may improve quality of life in type 2 diabetes. Diabetes Res Clin Pract. 2001;51(1):21-7.

39. McDonald S, Taylor L, Adams C. Searching the right database. A comparison of four databases for psychiatry journals. Health Libr Rev. 1999;16(3):151-6.

\section{Publisher's Note}

Springer Nature remains neutral with regard to jurisdictional claims in published maps and institutional affiliations.

Ready to submit your research? Choose BMC and benefit from:

- fast, convenient online submission

- thorough peer review by experienced researchers in your field

- rapid publication on acceptance

- support for research data, including large and complex data types

- gold Open Access which fosters wider collaboration and increased citations

- maximum visibility for your research: over $100 \mathrm{M}$ website views per year

At $\mathrm{BMC}$, research is always in progress.

Learn more biomedcentral.com/submissions 